\title{
Estimation of Semiconductor Switching Losses under Hard Switching using Matlab/Simulink Subsystem
}

\author{
Volodymyr Ivakhno (Professor, National Technical University "Kharkiv Polytechnic Institute”), \\ Volodymyr Zamaruiev (Professor, National Technical University "Kharkiv Polytechnic Institute"), \\ and Olga Ilina (Senior Lecturer, National Technical University "Kharkiv Polytechnic Institute”)
}

\begin{abstract}
The conventional tools for the system level simulation of the switch-mode power converters (for example, MATLAB/SIMILINK) allow simulating the behavior of a power converter jointly operating with the control system in a closed automatic regulation system. This simulation tools either represent semiconductor devices as ideal switches or implement the simplest models based on volt-ampere characteristics of standard types of semiconductor devices for conducting loss estimation. This fact makes direct calculation of dynamic power losses in the semiconductor devices impossible. The MATLAB/SIMILINK subsystem that calculates the average power dissipated in the power switch during turn-on and turn-off transition is proposed in this paper. The represented approach used in the subsystem estimates by the means of MATLAB/SIMILINK the values of turn-on and turn-off energies at power switch commutation instances on the base of switching current and voltage measurements and the values of commutation energies given in datasheet on power switch. The simulation results of step-down converter with IGBT and proposed subsystem in MATLAB/SIMULINK were compared with the calculation results obtained in Semisel.
\end{abstract}

Keywords - Power semiconductor switches, MATLAB, semiconductor device modeling, switching loss, circuit simulation.

\section{INTRODUCTION}

In recent years, powerful instruments for computer simulation of the power electronic systems have been developed. They allow solving a large number of various tasks, including: 1) - simulation of the mixed analog-digital devices at schematic level; 2) - simulation of the behavior of a power electronics circuit at system level [1].

Detailed analysis of electromagnetic processes in switchmode power converters can be conducted when simulating the mixed analog-digital devices with the use of detailed models of components. When simulating the behavior of a power converter jointly operating with the control system in a closed automatic regulation system, for the purpose of adjusting control system parameters, it is allowable to use the simplified models of components [2]. However the process of selecting the topology, components and operating parameters (voltage, current and switching frequency) of power converter is highly affected by the anticipated converter losses.

The analysis of the main electromagnetic processes in the system with power converters requires solving the system of differential equations, which describe the operation of the power electronic converter, using an appropriate time step through numeral methods [3], [4] and [5]. In this case it is sufficiently to represent semiconductor devices of power converter as ideal switches. An ideal switch changes from its on-state to its off-state instantaneously. In the on-state of an ideal switch its resistance and voltage drop on it are negligible; in the off-state switch resistance is significantly higher than the resistance of other components. Very important criterion for the implementation of such model is the ratio between the switching and conducting time intervals of a real switch. If the length of switching interval is considerably smaller than the length of interval during which the switch conducts current, and switching losses are negligible, it is acceptable to use the model of an ideal switch.

The conventional tool for the system level simulation of power converters is the software environment MATLAB that includes SIMULINK package with the library of SimPowerSystems blocks. Power semiconductors are either represented as ideal switches or apply the simplest models based on volt-ampere characteristics of standard types of semiconductor devices - diodes, metal-oxide-semiconductor field effect transistors (MOSFET), insulated-gate bipolar transistors (IGBT), thyristors (SCR), gate turn-off thyristors (GTO) - to take into account conduction losses. Switching of the semiconductors in such models is supposed instant, i.e. it is impossible to estimate the switching losses.

For the simulation of power converter systems at more detailed level PSpice A/D, which is a part of the software package OrCAD, is generally accepted [6]. The advantage of PSpice is higher extent of power semiconductor model specification that makes it possible to receive adequate current and voltage waveforms in power switches during switching processes, taking into account the influence of parasitic parameters of components, etc.

Complete PSpice model of MOSFET, for example, can include more than 50 various physical parameters [6]. In the simplified versions of models the number of the used parameters does not exceed 15 that significantly reduces the accuracy of simulation results. A number of model parameters can be specified comparing the simulation and experimental results [6], [7], [8] and [9].

Most of developers of semiconductor devices provide PSpice models of the IGBT, MOSFET and other devices well after their release [10]. In the latest versions of MATLAB/SIMULINK there appeared a new toolbox SimElectronics, which imports SPICE net lists containing semiconductor devices, sources, and passive SPICE components. However, directly connecting SimElectronics blocks to SimPowerSystems block is not allowed. 
Apart from PSpice and similar simulation modeling software products static models from leading manufactures of power semiconductor devices (Mitsubishi, Infineon, Semikron) allow loss and temperature calculation of power electronic devices - Melcosim, Iposim and Semisel software products respectively.

They, unlike SIMULINK, are not based on the solution of systems of the differential equations. Limited (though quite extensive) set of standard power circuit topologies with standard control algorithms of power switches is available to the analysis in this programs.

\section{Power Loss CAlculation Algorithm}

The selection of semiconductor device in definite application is influenced by a ratio of static (conducting) and dynamic (switching) losses in the power switch at attainable for given technology of device switching frequency.

Conducting losses can be calculated using linear approximation of power switch static volt-ampere characteristic that corresponds to the switch on-state equivalent circuit represented by series connection of the voltage source with the known value of threshold voltage $V_{(T O)}$ and the resistor with the known value of differential resistance $r_{T}$. Thereto average $I_{A V}$ and effective $I_{R M S}$ currents of the power switch for the chosen type of power converter should be defined. The average power of static losses $P_{s t}$ is:

$$
P_{s t}=I_{A V} \cdot V_{(T O)}+I_{R M S}^{2} \cdot r_{T} \text {. }
$$

Dynamic losses are defined on the basis of dependence between the energy dissipation during commutation (turn-on energy $E_{\text {on }}$ and turn-off energy $E_{\text {off }}$ ) for the concrete type of device and parameters of switching process - switched currents and voltages.

Dependencies of the switching energy dissipations on the switched currents and voltages are given in data sheet on the device of the chosen type. For example, for IGBT of the power module SK60GAR123 from Semikron with rated current $I_{\text {Cnom }}=50 \mathrm{~A}$, rated voltage $V_{\text {CCnom }}=600 \mathrm{~V}$ and blocking voltage $V_{C E S}=1200 \mathrm{~V} \quad-E_{\text {on }}=9.9 \cdot 10^{-3} \mathrm{~J}$, $E_{\text {off }}=5.3 \cdot 10^{-3} \mathrm{~J}$.

Switching energy dissipations can be approximated as linear functions of the collector current, which means for a first approach that these energies are proportional to the current [11]:

$$
\begin{gathered}
E_{\text {on }}\left(I_{C}\right)=E_{\text {on }}\left(I_{\text {Cnom }}\right) \cdot\left(\frac{I_{C}}{I_{\text {Cnom }}}\right) \cdot\left(\frac{V_{C C}}{V_{\text {CCnom }}}\right)^{K_{V},} \\
E_{\text {off }}\left(I_{C}\right)=E_{\text {off }}\left(I_{\text {Cnom }}\right) \cdot\left(\frac{I_{C}}{I_{\text {Cnom }}}\right) \cdot\left(\frac{V_{C C}}{V_{\text {CCnom }}}\right)^{K_{V}},
\end{gathered}
$$

where:

$V_{C C}, I_{C}-$ actual switched voltage and current values;

$V_{C \text { Cnom }}, I_{\text {Cnom }}-$ reference values of the switching loss measurement taken from the datasheet;

$K^{V}$ - exponent for the voltage dependency on the switching losses.
In standard cases the actual and rated switched voltages coincide $\left(V_{C C}=V_{C C n o m}=600 \mathrm{~V}\right.$ for the IGBT with the blocking voltage of $1200 \mathrm{~V})$. Standard value of the exponent $K^{V}$ for $1200 \mathrm{~V} \mathrm{IGBT}$ produced by Semikron is 1.4 , for $1700 \mathrm{~V}$ IGBT $-K^{V}=1.35$ [12].

For a semiconductor device that switches at frequency $f_{s w}$ the average power of switching losses can be defined from the switching energy dissipations calculated according to (2) as the following:

$$
P_{s w}=\left(E_{\text {on }}+E_{\text {off }}\right) \cdot f_{\text {sw }} .
$$

Expression (3) is correct provided constancy of switched currents and voltages; otherwise it is necessary to integrate energy losses within the period. The total losses in a semiconductor switch are obtained as a sum of static losses $P_{s t}$ from (1) and dynamic losses $P_{s w}$ from (3).

The represented method is used in Semisel for the calculation of energy losses and junction temperature [13]. The parameters of power devices, which determine the corresponding power losses, are available in a database of the program and are automatically defined by the choosing of the device type. It is supposed that the converter has ideal power filters and, therefore, switched IGBT currents in turn-on and turn-off intervals are equal.

As Semisel is not the imitating program, the user is deprived of opportunity to observe currents and voltage waveforms in the scheme, to consider real parameters of power filters, to use nonstandard control algorithms and converter topologies.

Calculation of dynamic losses in the semiconductor devices, used for the general assessment of characteristics of analyzed converting system, can be realized by means of MATLAB/SIMULINK.

\section{DyNAmic Characteristics OF POWER SWITCH}

Switching waveforms of the IGBT in a circuit under a clamped inductive load at the first approach are shown in Fig.1(a) [14], where $V_{\text {in }}$ - switch voltage, $I_{o}$ - switch current. Switching process has finite duration: turn-on $-t_{o n}$, switching off $-t_{\text {off }}$. Time diagram of the instantaneous loss power is shown in Fig.1(b). Power dissipation during turn-on $\left(p_{o n}\right)$ and turn-off $\left(p_{\text {off }}\right)$ of a switch is defined by the finite speed of switching process and nonzero values of current/voltage in the switching intervals. The corresponding values of switching energy at certain values of the switched voltage $V_{\text {in }}$ and current $I_{o}-E_{\text {on }}$ and $E_{\text {off }}-$ are reference values from the semiconductor device datasheet [15]. Static losses in switch are represented by conducting losses $-p_{\text {con }}$.

Models of power switches and calculation algorithm of MATLAB system assume instant switching of a power switch. Current and voltage waveforms at such switching process are shown in Fig.2. On the axis of abscissas the numbers of calculation steps are marked.

At existing model of power switch only static losses can be calculated. Dynamic losses cannot be considered due to the absence of commutation process in power switch - switching happens instantly after receiving of the control signal $V_{c n t r}$. 
(a)

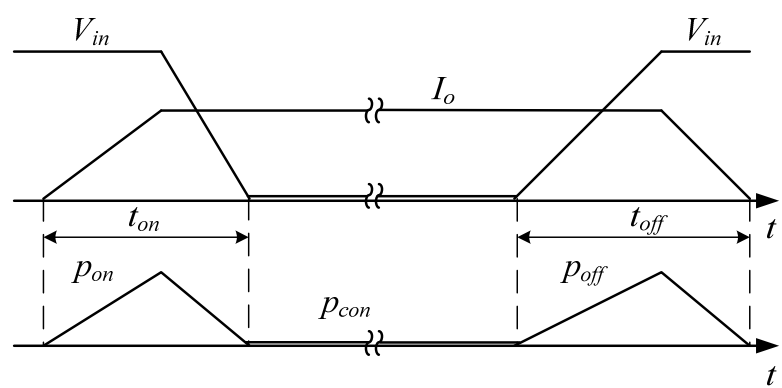

Fig.1. Switching waveforms and loss power of power switch.

However, as turn-on energy $E_{\text {on }}$ and turn-off energy $E_{\text {off }}$ are semiconductor device parameters given in the datasheet of semiconductor device, they can be associated with the corresponding moments of switching. In this case turnon/turn-off energy dissipation is represented by $\delta$ impulse with singular amplitude at the switching point (Fig.2(c)).

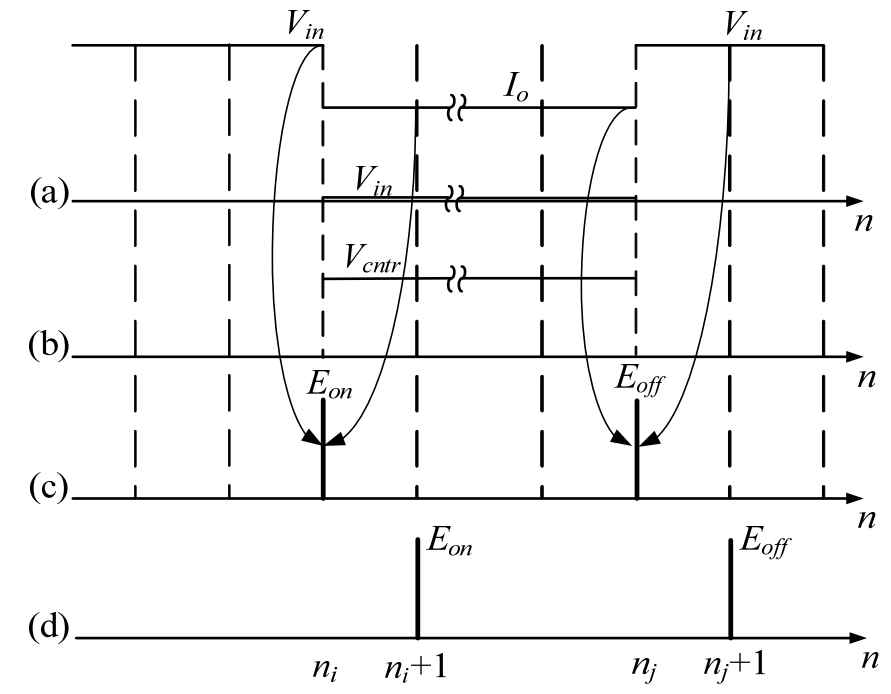

Fig.2. Switching process of power switch in MATLAB/SIMULINK.

For the calculation of switching energy dissipation according to (3) it is necessary to know current and voltage values at the switching point (more precisely, at turn-on voltage value before the switching point, and current value after it, and at turn-off - current value before the switching point, and voltage value - after it). According to the calculation algorithm of MATLAB, at the time of appearance of control signal $V_{c n t r}\left(\operatorname{step} n_{i}\right)$ switch voltage corresponds to the demanded value, however current yet did not change the value. Switching current can be received on a step $\left(n_{i}+1\right)$. Similarly, at switch turn-off (step $n_{j}$ ) the switching current corresponds to the demanded value, and switching voltage can be received on a step $\left(n_{j}+1\right)$. The process of data acquisition is shown in Fig.2 by arrows. The calculated value of energy cannot be received earlier than on $\left(n_{i}+1\right)$ and $\left(n_{j}+1\right)$ steps (Fig.2(d)). Time interval between the moment of commutation and the moment of obtaining the value of switching current/voltage can be increased in the case of existence of transients at the time of switching, for example, caused by computing instability of the system.

\section{Simulink SubSyStem FOR SWitching LosS CALCULATION}

According to the offered algorithm of dynamic losses calculation, the measuring subsystem has to be connected to the SIMULINK model of a power switch $S$ so that to provide the supervision of power switch control signal, the measurement of switch voltage and current. The scheme of connection is given in Fig.3.

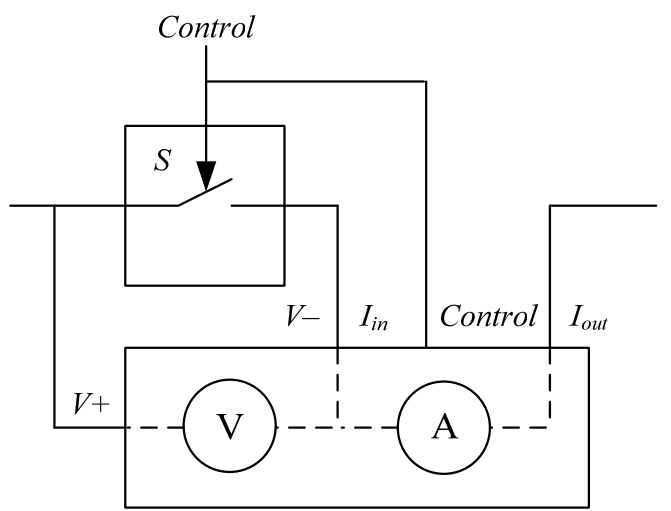

Fig.3. Connection of the measurement subsystem to the power switch.

The block diagram of the measuring subsystem is given in Fig.4. The subsystem includes three channels. The channel of current and voltage measurement corresponds to Fig.3. The channels of turn-on and turn-off energy loss computation operate in accordance with the algorithm given above and illustrated with Fig.2. For the detection of the power switch turn-on/turn-off moments Hit Crossing blocks, rising and falling edges respectively, and for obtaining value of a variable to the right of a switching point - Memory block are used.

Calculations are carried out according to expressions (2). For time matching of pulse signals of $I_{\text {on }(+0)}$ and $U_{\text {on( }(-0)}, I_{\text {off }(-0)}$ and $U_{\text {off( }+0)}$ Memory 2 and Memory3 blocks are installed. The measurement subsystem forms output pulse signals with the value of turn-on/turn-off energy losses one calculation step before the switching point.

To simplify data input for SK60GAR123 IGBT it is possible to use the $\mathrm{m}$-file with the following contents:

$$
\begin{aligned}
& \text { Eon_base }=9.9 \mathrm{e}-3 \\
& \text { Ion_base }=50 \\
& \text { Uon_base }=600 \\
& \text { Eoff_base }=5.3 \mathrm{e}-3 \\
& \text { Ioff_base }=50 \\
& \text { Uoff_base }=600 \\
& \mathrm{Kv}=\overline{1} .4
\end{aligned}
$$

For conversion from the pulse signals corresponding to loss energy, to more traditional representation - the power of losses, value of energy is integrated in time (discrete values are summarized) and the result is averaged during measurement. One of the possible versions of the subsystem for conversion from discrete values of loss energy to the average loss power is given in Fig.5. 



Fig.4. Simulink measurement subsystem for turn-on/turn-off loss energy calculation. Block $E_{\text {on__ }} E_{\text {off }}$.

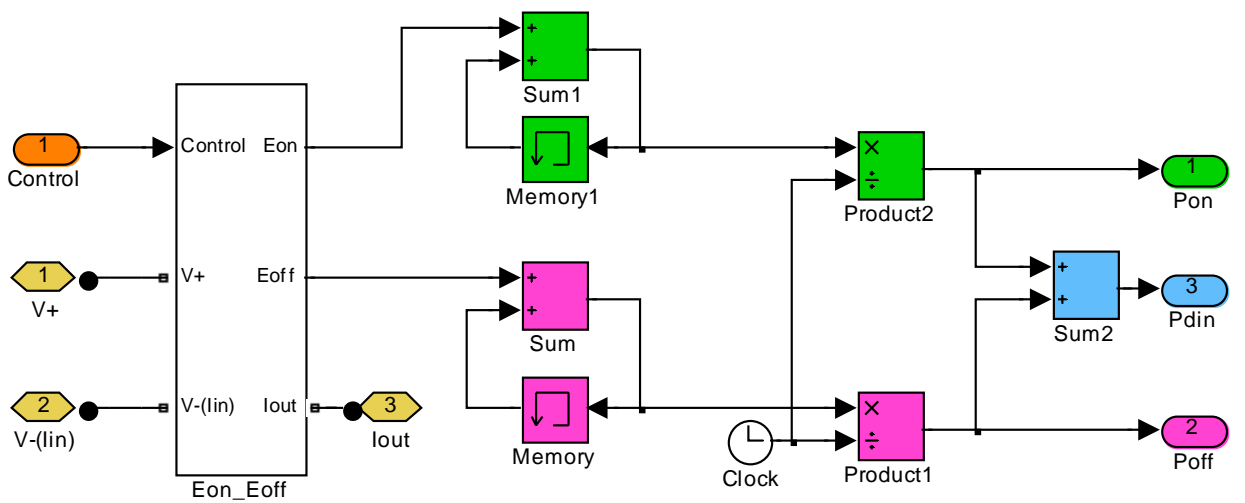

Fig.5. Simulink subsystem for conversion from loss energy to loss power. Block $\mathrm{P}_{\text {on_- }} \mathrm{P}_{\text {off. }}$ 


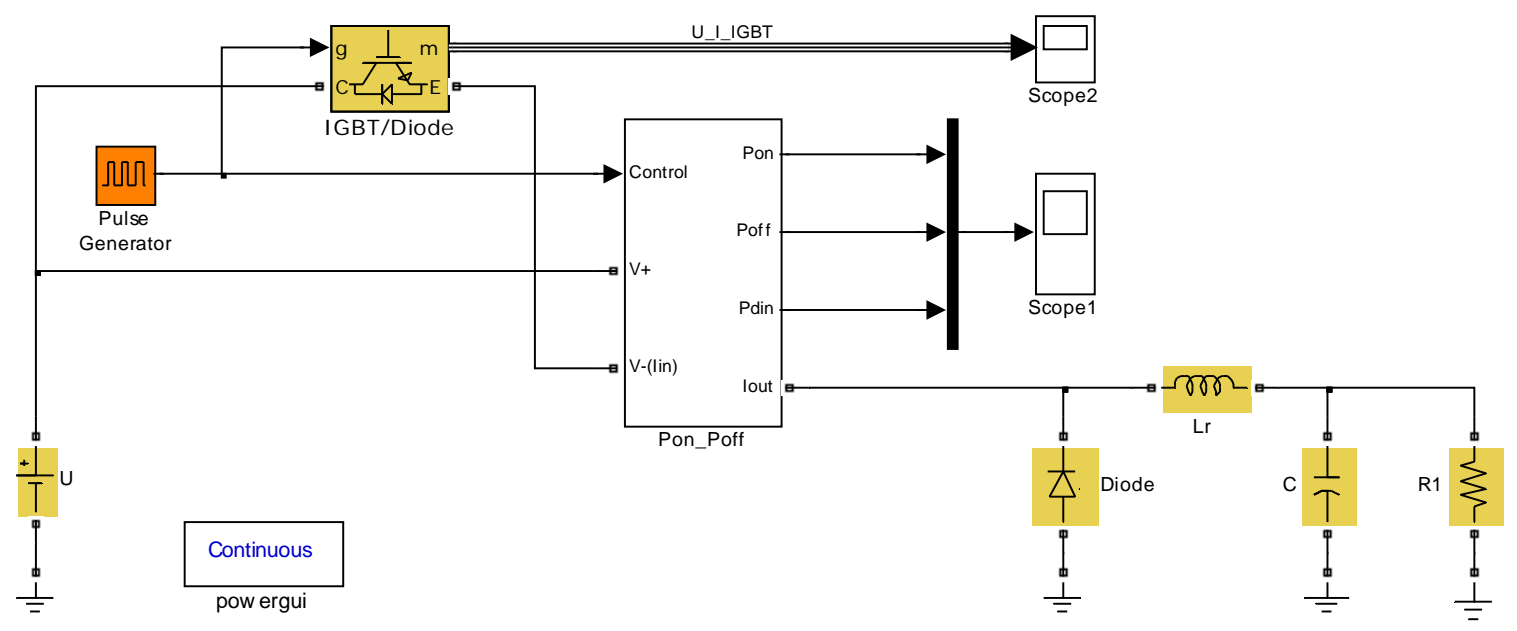

Fig.6. Simulink model of step-down converter test circuit.

The measurement subsystem for turn-on/turn-off energy loss calculation is presented by the $\mathrm{E}_{\text {on__ }} \mathrm{E}_{\text {off }}$ block.

Current and energy waveforms in Simulink model of stepdown converter (see Fig.6) are shown in Fig. 7 and 8 for low and high ripple current mode respectively. In both cases only the inductance values $L_{r}$ are different. The abscissa is the time of process and ordinates are conventional units of current and energy. As it can be seen from the analysis of Fig.7 and 8, the proposed strategy allows computation of the turn-on and turnoff energies as pulses at commutation moment. This approach takes into account differences between switch-on and switchoff currents.

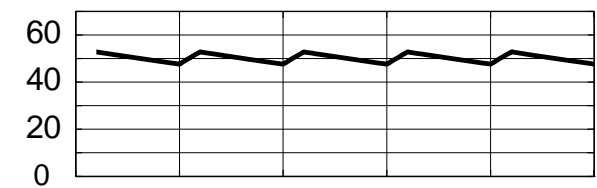

(a)

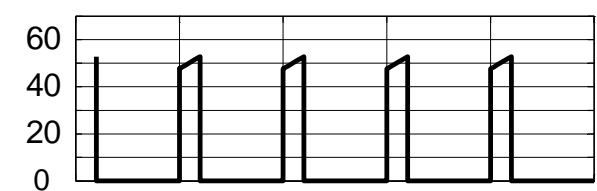

(b)
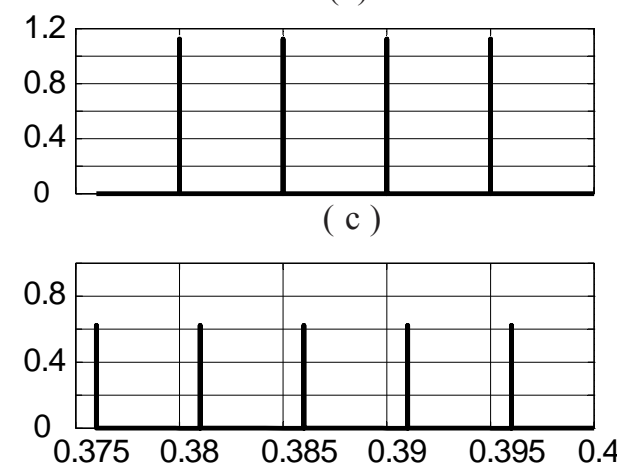

(d)

Fig.7. Current and energy waveforms in Simulink model of step-down converter with current ripple factor $K_{i}=0.05$ : inductance current $i_{L r}(\mathrm{a})$, switch current $i_{I G B T}(\mathrm{~b})$, pulses of turn-on energy $E_{\text {on }}(\mathrm{c})$ and of turn-off energy $E_{\text {off }}$ (d).
Sum and Memory blocks carry out summation with accumulation of discrete values of energy losses. At the output of the subsystem average value of power losses during measurement is formed.

The test circuit of the converter, which MATLAB/SIMULINK model is shown in Fig.6, has been made in order to validate the proposed techniques of dynamic loss calculation in power semiconductor devices. As the basic converter the step-down converter with the IGBT SK60GAR123 module is chosen. The subsystem for the calculation of average power of dynamic losses is presented by means of $\mathrm{P}_{\text {on_ }} \mathrm{P}_{\text {off }}$ block.

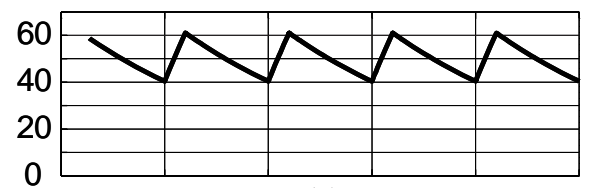

(a)

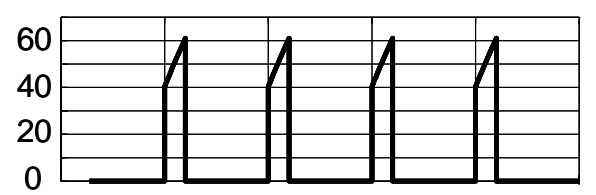

(b)
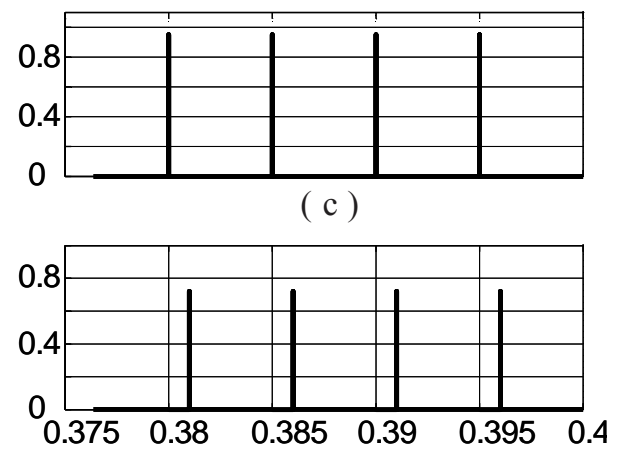

(d)

Fig.8. Current and energy waveforms in Simulink model of step-down converter with current ripple factor $K_{i}=0.2$ : inductance current $i_{L r}$ (a), switch current $i_{I G B T}(\mathrm{~b})$, pulses of turn-on energy $E_{\text {on }}(\mathrm{c})$ and turn-off energy $E_{\text {off }}(\mathrm{d})$. 
The comparison of calculations of average power losses in MATLAB/SIMULINK and Semisel was carried out for three operating modes of the scheme, differing by the voltage on IGBT and the load current. The obtained data are tabulated.

TABLE I

LOSS POWER OF IGBT SK60GAR123 IN STEP-DOWN CONVERTER CALCULATED IN MATLAB/SIMULINK AND SEMISEL

\begin{tabular}{|c|c|c|c|}
\hline IGBT & Load & \multicolumn{2}{|c|}{ Loss power, W } \\
\cline { 3 - 4 } voltage, & current, & Semisel & MATLAB \\
\hline V & $\mathbf{A}$ & 35 & 38 \\
\hline 600 & 25 & 13 & 14,4 \\
\hline 300 & 25 & 30 & 29 \\
\hline 300 & 50 & \multicolumn{2}{|c|}{} \\
\hline
\end{tabular}

The analysis of the obtained data allows drawing a conclusion on coincidence of simulation results in MATLAB/SIMULINK system with those theoretically expected. The discrepancy of the loss power received in MATLAB and Semisel is from the admissible range of 3-9\%.

\section{V.CONCLUSIONS}

The suggested approach to the estimation of dynamic losses in power switches combines the possibilities of such programs as Semisel to calculate power losses using reference values from datasheet on semiconductor device with the functionality of MATLAB/SIMULINK. This approach allows estimating dynamic losses in power switches of switch-mode power converter of whichever topology, which operates in a closed automatic regulation system with unconventional control algorithm. The acceptable accuracy of dynamic loss calculation $(<10 \%)$ is achieved only under hard switching, since power dissipation energy values given in datasheet are specified only for this mode. Semiconductor power losses, calculated in SIMULINK subsystem, have no influence on electromagnetic processes in the whole system. This restricts the functionality of the proposed subsystem especially in power converters with low efficiency.

\section{REFERENCES}

[1] S. Rossado et al, Modeling of power electronics for simulation based analysis of power systems, SCSC '07, San Diego, CA, USA, 2007, pp. 19-26.

[2] R. Araújo, V. Leite, D. Freitas, Modelling and simulation of power electronic systems using a bond graph formalism. In 10th Mediterranean Conference on Control and Automation. Lisboa, Portugal, 2002. [Online] Available: https://bibliotecadigital.ipb.pt/bitstream/10198/2225/ 1/avtl_MED02.pdf [Accessed: Jan. 20 2013].

[3] V.N. Katsikis, MATLAB - A Fundamental Tool for Scientific Computing and Engineering Applications - Volume 1, InTech, 2012 $520 \mathrm{p}$.

[4] MATLAB for Engineers - Applications in Control, Electrical Engineering, IT and Robotics, Edited by Dr. Karel Perutka, InTech, $2011512 \mathrm{p}$.
[5] Gole, A.M.; Keri, A.; Kwankpa, C.; Gunther, E.W.; Dommel, H.W.; Hassan, I.; Marti, J.R.; Martinez, J.A.; Fehrle, K.G.; Tang, L.; McGranaghan, M.F.; Nayak, O.B.; Ribeiro, P.F.; Iravani, R.; Lasseter, R., "Guidelines for modeling power electronics in electric power engineering applications," Power Delivery, IEEE Transactions on , vol.12, no.1, pp.505,514, Jan 1997

[6] M. H. Rashid, H. M. Rashid. SPICE for Power Electronics and Electric Power. Second Edition - CRC Press, Taylor \& Francis Group, $2006-$ $530 \mathrm{p}$.

[7] Cotorogea, M., "Physics-Based SPICE-Model for IGBTs With Transparent Emitter," Power Electronics, IEEE Transactions on , vol.24, no. 12 , pp. 2821,2832 , Dec. 2009

[8] I. Nedoluzhko, A. Lebedev. The method of calculating IGBT transistors PSPICE models (Metodika opredelenia parametrov PSPICE modolej IGBT tranzistorov) // Silovaja elektrohika №2, 2005 pp. 100-103 / in Russian

[9] Bryant, A.T.; Xiaosong Kang; Santi, E.; Palmer, P.R.; Hudgins, J.L., "Two-step parameter extraction procedure with formal optimization for physics-based circuit simulator IGBT and p-i-n diode models," Power Electronics, IEEE Transactions on , vol.21, no.2, pp.295,309, March 2006

[10] A.I. Kolpakov. Simulation of IGBT transistors using PSPICE (Modelirovanie tranzistorov IGBT $\mathrm{s}$ pomoshchju PSPICE) // Komponenty i tehnologii 2002. № 8 pp. 134- 139 / in Russian

[11] A.I. Kolpakov, Kartashov E.E. Concepts and Features of thermal calculation SEMISEL (Principy raboty i osobennosti programmy teplovogo pascheta SEMISEL) // Elektronnye komponenty (silovaja elektronika) M.-2004.№6. pp. 94-102 / in Russian

[12] I. Staudt, A. Wintrich, K. Haddad , V. Cardi, "Numerical loss calculation and simulation tool for 3L NPC converter design", The International Conference PCIM Europe 2011, Nuremberg

[13] SEMISEL Simulation. http:// www.semikron.com/ skcompub/ en/ index.htm ? mode $=$ semisel

[14] N. Mohan First courses on power electronic and drives - MNPERE, Minneapolis, 2003-251p.

[15] Datasheet SK60GAL123 http:// www.semikron.com/ products/ data/ cur/ assets/SK_60_GAR_123_24602801.pdf 


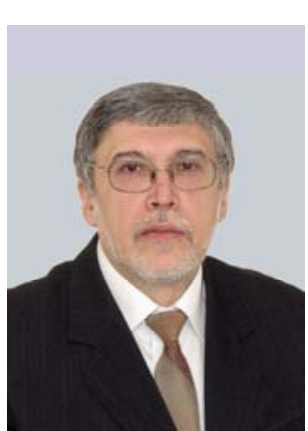

Volodymyr V. Ivakhno received the Ph.D. degrees in electrical engineering from Kharkiv Polytechnic Institute, Ukraine, in 1989. Title of thesis: "Control systems of too-stage convertors based on series resonant invertors". From 1982 to 1991 , he served as a research engineer in Industrial Electronics Department of Kharkiv Polytechnic Institute. In 1995 he joined the faculty of National Technical University "Kharkiv Polytechnic Institute" where he currently holds the rank of Full Professor of Industrial and Biomedical Electronics Department. He has published over 100 papers, including 9 patents. His interests include power semiconductor switches, soft commutation, electric power conversion, etc.

Postal address: Electric machine industry department, National Technical University "Kharkiv Polytechnic Institute", Frunze str. 21, Kharkiv 61002, Ukraine.

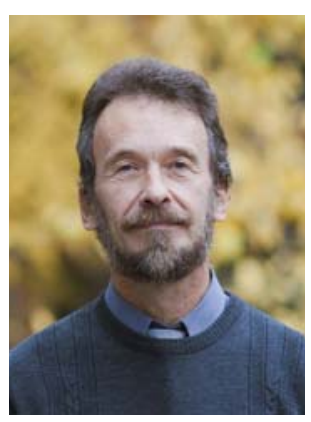

Volodymyr V. Zamaruiev received the $\mathrm{Ph} . \mathrm{D}$. degrees in electrical engineering from Kharkiv Polytechnic Institute, Ukraine, in 1996. Title of thesis: "Converter based on resonant inverter for pulse load". From 1982 to 1995, he served as a research engineer in Industrial Electronics Department of Kharkiv Polytechnic Institute. In 1995 he joined the faculty of National Technical University "Kharkiv Polytechnic Institute" where he currently holds the rank of Full Professor of Industrial and Biomedical Electronics Department. He has published over 100 papers, including 12 patents. Co-author of book "Special-purpose microcontroller system" (Kharkiv, 2007). His interests include power electronics and embedded system design.

Postal address: Electric machine industry department, National Technical University "Kharkiv Polytechnic Institute", Frunze str. 21, Kharkiv 61002, Ukraine.

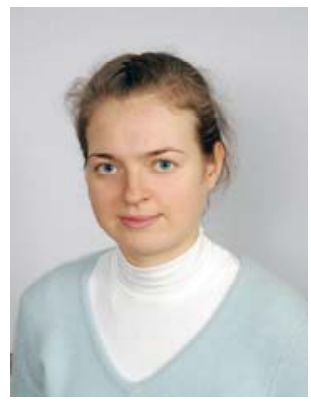

Olga V. Ilina received Master degree in electronic systems from National Technical University "Kharkiv Polytechnic Institute", Ukraine, in 2005 and the Ph.D. degree in electrical engineering from High Attestation Committee of Ukraine, in 2008. Title of thesis: "Energy saving semiconductor power converters for distribution power system". Since 2008, she has been a senior Lecturer of the Department "Industrial and biomedical electronics" of the National Technical University "Kharkov Polytechnic Institute". Her research interests include power electronics, power active filters, high-power electrical drive systems.

Postal address: Electric machine industry department, National Technical University "Kharkiv Polytechnic Institute", Frunze str. 21, Kharkiv 61002, Ukraine. 